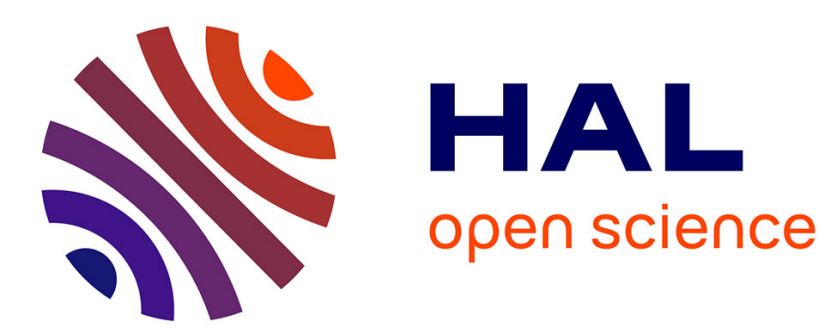

\title{
Inflation and Monetary Dynamics in the US: A Quantity-Theory Approach
}

Claudio Morana, Fabio Bagliano

\section{To cite this version:}

Claudio Morana, Fabio Bagliano. Inflation and Monetary Dynamics in the US: A Quantity-Theory Approach. Applied Economics, 2006, 39 (02), pp.229-244. 10.1080/00036840500428047 . hal-00581950

\section{HAL Id: hal-00581950 https://hal.science/hal-00581950}

Submitted on 1 Apr 2011

HAL is a multi-disciplinary open access archive for the deposit and dissemination of scientific research documents, whether they are published or not. The documents may come from teaching and research institutions in France or abroad, or from public or private research centers.
L'archive ouverte pluridisciplinaire HAL, est destinée au dépôt et à la diffusion de documents scientifiques de niveau recherche, publiés ou non, émanant des établissements d'enseignement et de recherche français ou étrangers, des laboratoires publics ou privés. 


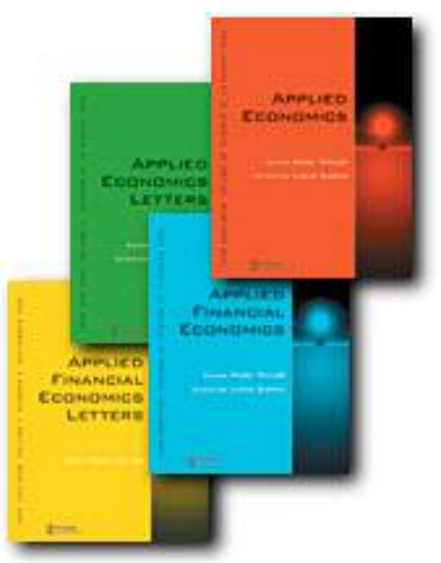

Inflation and Monetary Dynamics in the US: A Quantity-Theory Approach

\begin{tabular}{|c|c|}
\hline Journal: & Applied Economics \\
\hline Manuscript ID: & APE-05-0268.R1 \\
\hline Journal Selection: & Applied Economics \\
\hline $\begin{array}{r}\text { Date Submitted by the } \\
\text { Author: }\end{array}$ & 19-Jul-2005 \\
\hline JEL Code: & $\begin{array}{l}\text { C22 - Time-Series Models < C2 - Econometric Methods: Single } \\
\text { Equation Models < C - Mathematical and Quantitative Methods, E31 } \\
\text { - Price Level|Inflation|Deflation < E3 - Prices, Business } \\
\text { Fluctuations, and Cycles < E - Macroeconomics and Monetary } \\
\text { Economics, E52 - Monetary Policy (Targets, Instruments, and } \\
\text { Effects) < E5 - Monetary Policy, Central Banking, and the Supply of } \\
\text { Money and Credit < E - Macroeconomics and Monetary Economics }\end{array}$ \\
\hline Keywords: & $\begin{array}{l}\text { inflation, money growth, quantity theory, long memory, fractional } \\
\text { cointegration }\end{array}$ \\
\hline
\end{tabular}




\title{
Inflation and Monetary Dynamics in the US: A Quantity-Theory Approach
}

\author{
July 2005
}

\begin{abstract}
In this paper we investigate the long-run link between inflation and money growth in the US since 1960. A measure of the long-run inflation trend is constructed, which bears the interpreation of "monetary" inflation rate and is directly related to the excess nominal money growth process (money growth less output growth) as postulated by the quantity theory. Consistent with the memory characteristics of the series, their fractional integration and cointegration properties are taken into account in empirical modelling. The proposed measure is then compared with several existing measures of "core inflation", aimed at capturing long-run inflation dynamics but unrelated to money growth. The "monetary" long-run inflation rate performs well in out-of-sample forecasting exercises especially over a two- to three-year horizon, yielding valuable information to monetary policymakers.
\end{abstract}

Keywords: inflation, money growth, quantity theory, long memory, fractional cointegration.

JEL classification: C22, E31, E52. 


\section{Introduction}

The relationship between inflation and money growth has always played a prominent role in monetary theory and policy. A one-to-one proportionality between changes in the steady-state money growth rate and the rate of inflation in the long-run is commonly regarded as an explanation of inflation grounded in the quantity theory of money (Nelson, 2003). This conception is summarized in the famous statement by Milton Friedman that "inflation is always and everywhere a monetary phenomenon" (Friedman (1963), restated in Friedman (1992)). The "steady-state" and "long-run" qualifiers motivated the empirical research aimed at establishing a link between the average inflation rate and the average rate of money growth over extended time periods in a cross-section of countries. The results by, among others, McCandless and Weber (1995), showing an almost unitary correlation between 30-year (1960-1990) averages of inflation and money growth rates in a cross-section of over one hundred countries, are considered by Lucas (1996) and Walsh (2003, chapter 1) as established stylized facts lending strong support to the quantity theory as a long-run theoretical and policy framework.

Recently, a lively debate has revived on the validity of the quantitytheory explanation of inflation and on its usefulness for policy purposes. On the theoretical side, models of the New-Keynesian variety widely used for policy advice do not make any reference to monetary aggregates, picturing monetary policy conduct in terms of interest rate rules, whereby a short-term policy interest rate is set with reference to (current or expected) inflation and a measure of output gap movements (Taylor, 1999), with the primary goal of price stability. However, McCallum (2001) argued that, even in the absence of explicit monetary terms in the main equations of the New-Keynesian model, inflation can still be regarded as determined in the long-run by the steadystate rate of nominal money growth relative to output growth, as predicted by the quantity theory.

On the empirical side, De Grauwe and Polan (2001), focusing on the group of low-inflation countries (less than $10 \%$ per year on average over three decades), showed that the proportionality between long-run averages of money growth and inflation is much harder to detect: inflation seems to be an exogenously driven phenomenon, mainly unrelated to money growth. This evidence has been interpreted as implying that, when inflation is relatively low, changes in the money growth rate are very noisy signals of inflationary pressures. Hence, monetary authorities like the European Central Bank should not regard money growth as a valuable information variable and should abandon the practice of setting "reference values" for the growth rate of some monetary aggregate (Begg et al., 2002; Svensson, 2002). How- 
ever, results by Batini and Nelson (2001), Leeper and Roush (2003) and Nelson (2003) have recently provided fresh evidence for the US and the UK supporting the basic "quantity-theory" proposition that inflation and money growth are strongly correlated once allowance is made for lags in the monetary transmission. Moreover, the analysis by Gerlach and Svensson (2003) and Bagliano et al. $(2002,2003)$ of the Euro-area experience since 1980 lends support to a $P^{*}$ model (Hallman et al., 1991) of the long-run relation between prices, monetary aggregates and output, while even a more direct reference to the quantity theory is made by Morana (2002, 2005), where the long-run quantity theory relationship is estimated.

In this paper we use the quantity theory as a general theoretical framework to investigate the link between the behavior of inflation and monetary growth in the long-run for the US economy from the early 1960s. The main result is a measure of the long-run trend in the inflation rate very closely linked to the dynamics of monetary aggregates and with interesting forecasting properties over the medium-term horizon (ranging from two to three years) relevant for monetary policy analysis. Our focus is on the common persistence properties of the inflation rate and the rate of monetary growth relative to output growth, which represents a novelty in the literature applied to US data. Our treatment of persistence allows inflation and money growth to follow more general processes than the $I(1)$ and $I(0)$ alternatives, modelling them as fractionally integrated series displaying long memory, i.e. the property that shocks may take a very long time to eventually die out. This choice is supported by the empirical results by, among others, Hassler and Wolters (1995) and Bos et al. (2002). Recent attempts to jointly model inflation and money growth in a common trends framework by Bagliano and Morana (2003) yielded a non-stationary, $I(1)$, measure of the inflation trend. Though the results of non-stationarity tests may support $I(1)$ modelling of the series over specific sample periods, the fractional integration framework seems less restrictive and more appropriate for inflation modelling when monetary authorities are relatively successful in keeping inflation under control.

Our paper contributes to the recent literature on the construction of measures of the underlying trend in inflation, commonly referred to as "core inflation", which has provided monetary analysts and policymakers with several different series claiming to capture the long-run trend of the inflation rate. The motivation for this literature is the effort of purging the actual inflation rate from the effect of non persistent components that should not affect the actions of monetary policymakers aiming at controlling inflation over a medium- to long-term horizon. In fact, only the movements in the inflation rate reflecting persistent sources of inflationary pressures should trigger a monetary policy reaction. 
Several measures, constructed with different methodologies, have been proposed and applied to US and other countries' data: univariate smoothing techniques (Cogley, 2002), purely statistical measures based on cross-section data (Bryan and Cecchetti 1993, 1994; Cecchetti, 1997), econometric estimates either based on long-run neutrality restrictions (Quah and Vahey, 1995) or obtained as the long-term forecast from a small-scale system of macroeconomic variables (Cogley and Sargent, 2001; Bagliano and Morana, 2003). The shared purpose of all these measures has been well laid out by Bryan and Cecchetti (1994), who define core inflation as the long-run, persistent component of the measured inflation rate, "which is tied in some way to monetary growth" (p.197). However, with the exception of the common trends model of Bagliano and Morana (2003), monetary growth does not play any role in the construction of the US core inflation series. The approach taken in this paper directly pursues the lead of Bryan and Cecchetti by estimating a measure of long-run inflation very closely linked to monetary dynamics, able to capture the inflationary potential embodied in the monetary aggregates, consistent with the common persistence properties of the series.

The remainder of the paper is organized as follows. The next section formalizes our concept of monetary inflation, clarifying the link between inflation and money growth in the simple framework provided by the quantity theory. Section 3 describes the econometric methodology adopted in the empirical analysis carried out in Section 4, where our monetary inflation series is estimated on quarterly US data spanning the 1959-2003 time period, and assessed in comparison with other measures of the long-run inflation trend. Finally, section 5 concludes.

\section{Long-run "monetary" inflation in a quantity- theory framework}

Our empirical investigation of the relation between inflation and monetary growth is cast in the theoretical framework provided by the quantity theory, according to which inflation is a monetary phenomenon, in the sense of a one-to-one relationship between the steady-state values of the inflation and monetary growth rates (Nelson (2003) provides an insightful discussion of the quantity theory proposition in the context of the recent monetary policy literature). This relationship can be derived directly from the equation of exchange by (log)first-differencing, obtaining

$$
\pi=m-y+v
$$


stating that the inflation rate, $\pi$, is equal to the growth rate of nominal money in excess of the rate of output growth, $m-y$, corrected for the drift in velocity, $v$.

Operationally, in accordance with the quantity theory, we describe the inflation rate as determined in the long-run by the following equation

$$
\pi_{t}=m_{t}-y_{t}+\varepsilon_{t}^{\pi}
$$

where $\varepsilon_{t}^{\pi}$ follows a stationary ARMA process. Hence, (1) relates the longrun inflation rate to the long-run nominal money growth rate in excess of output growth (henceforth called the "excess nominal money growth rate", $\left.e m_{t} \equiv m_{t}-y_{t}\right)$.

The persistence properties of the excess nominal money growth process are therefore inherited by the inflation rate through the quantity theory relationship. In our empirical framework both real output growth and nominal money growth are modelled as stationary long-memory processes $(I(d)$ $0<d<0.5)^{1}$ : it follows that also excess nominal money growth and inflation are stationary long-memory processes. Formally, we model the nominal money and real output growth rates as

$$
\begin{aligned}
m_{t} & =\mu_{l m, t}^{n}+\varepsilon_{t}^{m} \\
y_{t} & =\mu_{l m, t}^{r}+\varepsilon_{t}^{y},
\end{aligned}
$$

where $\mu_{l m, t}^{n} \sim I(d)$ and $\mu_{l m, t}^{r} \sim I(d)$, with $0<d<0.5$ (as motivated by the empirical results below), are the nominal long-memory component and the real long-memory component respectively, whereas $\varepsilon_{t}^{m}$ and $\varepsilon_{t}^{y}$ follow stationary zero mean ARMA processes. This implies that the excess nominal money growth

$$
e m_{t}=\mu_{l m, t}^{n}-\mu_{l m, t}^{r}+\varepsilon_{t}^{m}-\varepsilon_{t}^{y}
$$

and the inflation rate

$$
\pi_{t}=\mu_{l m, t}^{n}-\mu_{l m, t}^{r}+\varepsilon_{t}^{m}-\varepsilon_{t}^{y}+\varepsilon_{t}^{\pi}
$$

are stationary long-memory processes as well. The inflation rate is then the sum of the long-memory component of the excess money growth $\left(\mu_{l m, t}^{n}-\mu_{l m, t}^{r}\right)$ and of a composite term reflecting non persistent disturbances $\left(\varepsilon_{t}^{m}-\varepsilon_{t}^{y}+\varepsilon_{t}^{\pi}\right)$.

The long-run relationship (1) can then be empirically interpreted as a fractional cointegration relation, since

$$
\pi_{t}-e m_{t}=\varepsilon_{t}^{\pi}
$$

\footnotetext{
${ }^{1}$ When $0<d<0.5$ the process is stationary long-memory with all autocorrelations positive and decaying towards zero at a (slow) hyperbolic rate.
} 
is a weakly dependent process. Moreover, real money growth and output growth should be fractionally cointegrated. In fact, the above long-run relationship (6) can be rewritten as

$$
r m_{t}-y_{t}=-\varepsilon_{t}^{\pi}
$$

where $r m_{t} \equiv m_{t}-\pi_{t}$ is the real money growth process. Finally, we define $\pi_{t}^{*}$ as the sum of the estimated persistent nominal and real factors

$$
\pi_{t}^{*}=\hat{\mu}_{l m, t}^{n}-\hat{\mu}_{l m, t}^{r} \equiv \hat{\mu}_{l m, t} .
$$

By being directly related to the excess nominal money growth rate, this measure is immediately interpretable as a "monetary inflation rate", capturing the long-run inflation potential embodied in the dynamics of money and output growth, consistent with their common persistence properties. ${ }^{2}$

Figure 1 plots our raw data for inflation and money growth. The upper panels show the behavior of US CPI inflation over the 1959-2003 period both as a quarterly rate (left-hand panel) and as a 12-quarter backward moving average of quarterly rates (right-hand panel) to highlight the inflation trend over a medium-term horizon. The lower panels plot the growth rates of two monetary aggregates: $M 2$, which is the focus of most of the empirical literature on the money growth-inflation relation, and the broader aggregate $M 3$. Again, the quarterly rates and the 12-quarter moving averages of quarterly rates are shown. The two monetary aggregates are highly correlated: the correlation coefficient of the quarterly rates is 0.80 and the correlation of their first differences is 0.63 . As for their relation with the inflation rate, the cross-correlogram of the quarterly inflation and $M 3$ growth rates, showing the correlation of inflation at quarter $t$ and money growth at quarter $t-j$, peaks at 0.45 for $j=11$ and stays in the range $0.38-0.45$ for lags between 8 and 13 quarters, pointing to a delay of two-three years in the reaction of inflation to money growth. The growth rate of $M 2$ displays a similar pattern of cross-correlations with the inflation rate, but with lower coefficients.

In Figure 2 we plot the four variables (at the quarterly frequency) that will be the focus of the econometric analysis of the next sections; to highlight their long-run comovements, 12-quarter moving averages of all series are displayed over the 1962(1)-2003(2) period. The upper panel shows the inflation rate and the excess money growth rate (given by nominal $M 3$ growth less GDP growth); the lower panel displays the real money growth rate (nominal M3 growth less CPI inflation) and the GDP growth rate. In both cases the series tend to fluctuate together, although in the final part of the sample the excess

\footnotetext{
${ }^{2}$ See also Morana $(2002 ; 2004 b)$.
} 
money and real money growth rates display more pronounced swings than the inflation and output growth rates (for example, the upswing in excess money growth from early 2001 may be due to a shift in investors' portfolios towards liquid assets for precautionary reasons in the aftermath of the burst of the stock market bubble). The observation of these comovements motivates the detailed analysis of the common long-run behavior of the variables performed in the following sections.

\section{Econometric methodology}

Following Morana (2004a, 2005b), let us assume the following common long memory factor model

$$
\begin{aligned}
\mathbf{x}_{t} & =\Theta \boldsymbol{\mu}_{t}+\mathbf{u}_{t} \\
\Delta^{d} \boldsymbol{\mu}_{t} & =\varepsilon_{t},
\end{aligned}
$$

where $\mathbf{x}_{t}$ is a $p \times 1$ vector of observations on $p$ fractionally cointegrated processes, $\boldsymbol{\mu}_{t}$ is a $k \times 1$ vector of unobserved long memory factors $(I(d)$, $0<d<0.5), \Theta$ is the $p \times k$ factor loading matrix with $k<p, \varepsilon_{t} \sim$ i.i.d. $\left(\mathbf{0}, \Sigma_{\varepsilon}\right)$ with dimension $k \times 1$ and $\Sigma_{\varepsilon}=\mathbf{I}_{k}, \mathbf{u}_{t}$ is a $p \times 1$ vector of unobserved weakly dependent components $(I(0))$ with $\Phi(L) \mathbf{u}_{t}=\Omega(L) \mathbf{v}_{t}$, all the roots of the polynomial matrices in the lag operator $\Phi(L)$ and $\Omega(L)$ are outside the unit circle, $\Phi(0)=\Omega(0)=\mathbf{I}_{p}$, and $\mathbf{v}_{t} \sim$ i.i.d. $\left(\mathbf{0}, \Sigma_{v}\right)$ with dimension $p \times 1$. In the empirical implementation of the next section, $\mathbf{x}$ will be a two-element vector including the candidate variables for fractional cointegration, namely either inflation and excess nominal money growth or real money growth and real GDP growth.

Applying fractional differencing to (9), yields

$$
\Delta^{d} \mathbf{x}_{t}=\Theta \varepsilon_{t}+\Delta^{d} \mathbf{u}_{t}
$$

with the associated spectral matrix

$$
\mathbf{f}(\omega)=\Theta \mathbf{f}_{\varepsilon}(\omega) \Theta^{\prime}+\Theta \mathbf{f}_{\varepsilon, \Delta^{d} u^{\prime}}(\omega)+\mathbf{f}_{\Delta^{d} u, \varepsilon^{\prime}}(\omega) \Theta^{\prime}+\mathbf{f}_{\Delta^{d} u}(\omega),
$$

where the $\mathbf{f}_{i}(\omega)$ matrices contain the spectral and cross-spectral functions for the given vectors, evaluated at the frequency $\omega$. Evaluation at the zero frequency yields

$$
\mathbf{f}(0)=\frac{1}{2 \pi} \Theta^{\prime},
$$


since, from the assumptions on $\mathbf{u}$ and $\varepsilon$ above, $\mathbf{f}_{\varepsilon, \Delta^{d} u^{\prime}}(0)=\mathbf{0}, \mathbf{f}_{\Delta^{d} u, \varepsilon^{\prime}}(0)=\mathbf{0}$, $\mathbf{f}_{\Delta^{d} u}(0)=\mathbf{0}$, and $\mathbf{f}_{\varepsilon}(\omega)=\frac{1}{2 \pi} \mathbf{I}_{k}$ at all frequencies. Since $\Theta \Theta^{\prime}$ is of reduced rank $k<p$, also $\mathbf{f}(0)$ will be of reduced rank equal to $k .^{3}$

The identification of $\Theta$, given the assumption of orthogonality of the factors, requires the imposition of $k(k-1) / 2$ equality restrictions on $\Theta$. Yet, in the case of interest for this paper, since $k=1, \Theta$ is identified (up to the sign) without additional restrictions. Assuming that $2 \pi \mathbf{f}(0)$ is known, a matrix $\mathbf{Q}^{*}$ such that $2 \pi \mathbf{f}(0)=\mathbf{Q}^{*} \mathbf{Q}^{* \prime}$ can be found by using the eigenvectors of $2 \pi \mathbf{f}(0)$ as discussed below.

Estimation of the factor loading matrix From the symmetry property, it follows that the spectral matrix can be factorised as

$$
2 \pi \mathbf{f}(0)=\mathbf{Q} \Lambda \mathbf{Q}^{\prime}
$$

where $\Lambda$ is the $k \times k$ diagonal matrix of (real) non-zero eigenvalues of $2 \pi \mathbf{f}(0)$ ordered in descending order and the matrix $\mathbf{Q}$ is the $p \times k$ matrix of the associated orthogonal eigenvectors. ${ }^{4}$ By writing $\mathbf{Q}^{*}=\mathrm{Q} \Lambda^{\frac{1}{2}}$, we then have

$$
2 \pi \mathbf{f}(0)=\mathbf{Q}^{*} \mathbf{Q}^{* \prime}
$$

The matrix $\hat{\mathbf{Q}}^{*}$, obtained from the largest eigenvalues of $2 \pi \hat{\mathbf{f}}(0)$ and the associated eigenvectors, is therefore our estimator of the factor loading matrix $\Theta$. See Morana (2004a) and Beltratti and Morana (2005) for details concerning consistency and asymptotic normality of the factor loading matrix estimator and identification and estimation in the general multivariate case.

Estimation of the cointegration space Given the orthogonality property of the eigenvectors, it follows that

$$
\mathbf{Q}_{1, . ., k}^{\prime} \mathbf{Q}_{k+1, . ., p}=\underset{k \times(p-k)}{\mathbf{0}},
$$

where $\mathbf{Q}_{1, . ., k}$ and $\mathbf{Q}_{k+1, \ldots, p}$ denote the submatrices composed of the $k$ eigenvectors associated with the first $k$ largest roots, and the last $r=p-k$ eigenvectors associated with the zero roots, respectively. Hence $\mathbf{Q}_{k+1, \ldots, p}$ is a right null space basis of the factor loading matrix, which is the definition of

\footnotetext{
${ }^{3}$ Note that the same results hold for the case in which the $\mathbf{u}$ vector is $I(b)$, with $b>0$ and $d-b>0$, since $\Delta^{d} \mathbf{u} \sim I(b-d)$, implying overdifferencing and hence a null spectral matrix at the zero frequency.

${ }^{4}$ Since $\mathbf{f}(0)$ is of reduced rank $k$, only $k$ eigenvalues are greater than zero.
} 
the cointegration space, since the cointegration relationships are the linear combinations of the variables which remove the persistent $(I(d))$ components from them. We can write therefore $\boldsymbol{\beta}=\mathbf{Q}_{k+1, \ldots, p}$, where $\boldsymbol{\beta}$ denote the $p \times r$ cointegration matrix, obtaining

$$
\boldsymbol{\beta}^{\prime} \mathrm{Q}^{*}=\boldsymbol{\beta}^{\prime} \Theta=\underset{r \times k}{\mathbf{0}} .
$$

The matrix $\hat{\mathbf{Q}}_{k+1, . ., p}$, obtained from the eigenvectors associated with the smallest eigenvalues of $2 \pi \hat{\mathbf{f}}(0)$, is therefore our estimator of the cointegration space. Note that the cointegration space is only identified up to an arbitrary rotation of coordinates, i.e. up to an orthogonal matrix of dimension $r$. As for the standard cointegration case, full identification then requires the imposition of additional $r^{2}$ restrictions, of which $r$ are normalization restrictions. Yet, in the case of interest for this paper, since $r=1$, the identification of $\boldsymbol{\beta}$ requires a single normalisation restriction. Monte Carlo simulations reported in Morana (2004a) show that the proposed approach has good properties with sample sizes as small as 100 observations. The performance of the estimator of the cointegration space is comparable to the narrow band frequency domain least square estimator of Robinson and Marinucci (2001), and, as shown in Morana (2004a, 2005b), in the case of know cointegrating vectors the two approaches are equivalent. A similar argument holds relatively to the approach of Chen and Hurvich (2002) which, for the stationary long memory case, amounts to (non tapered) narrow band frequency domain least squares estimation of the known cointegrating vectors. See also Morana (2005b) for details concerning the consistency of the estimator of the cointegration space and for details about identification in the general multivariate case.

Persistent-non persistent decomposition A persistent-non persistent decomposition (P-NP decomposition) of the observed variables can be performed through the decomposition of Kasa (1992), which can be written as

$$
\begin{aligned}
\mathbf{x}_{t} & =\Theta \mathbf{f}_{t}+\mathbf{u}_{t} \\
\mathbf{f}_{t} & =\left(\Theta^{\prime} \Theta\right)^{-1} \Theta^{\prime} \mathbf{x}_{t} \\
\mathbf{u}_{t} & =\boldsymbol{\beta}\left(\boldsymbol{\beta}^{\prime} \boldsymbol{\beta}\right)^{-1} \boldsymbol{\beta}^{\prime} \mathbf{x}_{t}
\end{aligned}
$$

where $\Theta\left(\Theta^{\prime} \Theta\right)^{-1} \Theta^{\prime} \mathbf{x}_{t}$ is the persistent (long memory component) and $\boldsymbol{\beta}\left(\boldsymbol{\beta}^{\prime} \boldsymbol{\beta}\right)^{-1} \boldsymbol{\beta}^{\prime} \mathbf{x}_{t}$ is the non persistent $(\mathrm{I}(0))$ component or the less persistent $\mathrm{I}(b)$ component $b>0, d-b>0$, when $\mathbf{u}_{t} \sim I(b) .{ }^{5}$ Hence, the vector $\mathbf{x}_{t}$ is decomposed in the

\footnotetext{
${ }^{5}$ The $\mathbf{u}_{t}$ vector is $\mathrm{I}(b)$ when the cointegrating residuals are $\mathrm{I}(b)$ or when the largest order of fractional integration of the cointegrating residuals is $\mathrm{I}(b)$. Note in fact that the $\mathbf{u}_{t}$ vector is computed as a linear combination of the cointegrating residuals.
} 
sum of its projections on $\Theta$ and $\boldsymbol{\beta}=\Theta_{\perp}$, where the projection operators are $\Theta\left(\Theta^{\prime} \Theta\right)^{-1} \Theta^{\prime}$ and $\boldsymbol{\beta}\left(\boldsymbol{\beta}^{\prime} \boldsymbol{\beta}\right)^{-1} \boldsymbol{\beta}^{\prime}$ (see Kasa, 1992). The decomposition has the merit of being implemented as a linear combination of the observed variables, not involving future observations of the processes, allowing to compute core inflation in real time.

\section{Empirical results}

This section describes the data set used and presents the empirical results, focusing first on the persistence properties of the variables and then on their fractional cointegration features. Finally, a measure of the inflation trend capturing the link with monetary and output growth is presented and its properties evaluated.

\subsection{Data}

The US data employed in this study are taken from the Federal Reserve Bank of St. Louis' FRED database. The inflation rate has been computed from the all-item consumer price index for all urban consumers (CPIAUCSL), and the gross domestic product figures are in billions of (chained) 1996 dollars (GDCP1). The three monetary aggregates $M 1, M 2$ and $M 3$ have been used in the empirical analysis; since, as noted below, the results are similar across aggregates, we report only those for the $M 3$ money stock series $(M 3 S L)$. All series are seasonally adjusted and sampled at the quarterly frequency. The sample period runs from 1959(1) to 2003(2).

In the following empirical analysis $\pi$ denotes the CPI inflation rate, $m$ is the growth rate of nominal $M 3$; the real $M 3$ growth rate is denoted by $r m \equiv m-\pi$, and $y$ is the real GDP growth rate. Finally, em denotes the nominal $M 3$ growth rate in excess of output growth; as in our discussion of the quantity theory framework in Section 2, we assume a unitary output elasticity of real money balances (justified by the empirical results reported below), and compute the excess nominal money growth rate as $m-y$.

\subsection{Persistence properties}

The first step in our empirical investigation consists of a careful analysis of the persistence properties of the variables. As mentioned in the preceding sections, we do not constrain the inflation rate and the other series used to be either $I(1)$ or $I(0)$, but consider the intermediate possibility of fractional integration, implying that shocks have long-lasting effects on the variables 
and die out only asymptotically. However, evidence of long-memory behavior might be spurious, being due to the occurrence of infrequent structural breaks in the series, as shown by Bos et al. (1999), Diebold and Inoue (2001), Granger and Hyung (2004) and Hyung et al. (2004). To address this issue, our analysis of the persistence properties of the data is carried out allowing for both deterministic (break process) and stochastic (long-memory) sources of persistence.

Three approaches have been followed to investigate the presence of a break process in the series analyzed, all of them allowing for long memory while testing for structural change. The first approach (Kokoszka and Leipus 2000) tests for the presence of breaks in long-memory processes, determining their location in the sample. The second approach (Morana, 2002), is based on an augmented Engle and Kozicki (1993) feature test. This test amounts to checking the statistical significance of a candidate break process in an autoregressive, fractionally integrated, moving average (ARFIMA) model, and exploits the result of Granger and Hyung (2004) that removing a spurious break process induces "antipersistence" in the data. Finally, the third approach, recently suggested by Dolado et al. (2004), is based on an augmented fractional Dickey-Fuller test.

Since a break process should capture infrequent changes in the variables, more reliable conclusions concerning the presence of structural changes should be drawn from series sampled at low frequency (see Morana and Beltratti, 2004). Therefore we begin our investigation of the presence of a break process using data sampled at the annual frequency from 1959 to 2002.

Table 1 summarizes the main results of the persistence and structural break analysis carried out on the annual series. The values of the Kokoszka and Leipus (2000) test for structural breaks in long memory processes $(K L)$ are reported in columns (1) and (2) of the table. Since this test can be sensitive to the assumed degree of long memory, the robustness of the results has been evaluated using two values for the fractional differencing parameter $d$, namely $d=0.20$ and $d=0.40$. As shown in the table, the results of the test are clear cut: none of the series shows evidence of structural breaks, irrespective of the value assumed for the fractional differencing parameter.

Results for the augmented Engle-Kozicki test are also reported in Table 1. The candidate break process has been estimated by means of a Markov switching model (Hamilton, 1990), which, as shown by Ang and Bekaert (2002), allows for consistent estimation of the break process, provided the omitted variables are not regime-dependent (see Morana (2002) for a discussion of other available approaches in the literature). Columns (4) and (5) show the Bayes-Schwartz information criterion for the linear (constantmean) model $\left(B I C_{1}\right)$ and the two-regime alternative $\left(B I C_{2}\right)$. Moreover, the 
$p$-values of the likelihood ratio test $(L R)$ for the null of a one-regime model against a two-regime alternative are displayed in column (6). ${ }^{6}$ These results suggest that a two-regime model can be selected for the inflation, nominal money growth and real money growth processes, whereas a single regime model seems appropriate for the real output and excess money growth rates. To assess the possibility that such tests detect spurious break processes, column (7) reports the values of the augmented Engle and Kozicki (1993) test for an ARFIMA model $\left(d_{E K, Y}\right)$ : the results of the test point to the presence of a spurious break process in all series apart from nominal money growth, a finding which contrasts with the results of the $K L$ test. However, since real money growth and inflation do not show compelling evidence of structural breaks, it is possible to conclude against the evidence of a break process also in nominal money growth. This conclusion is also supported by the results of the test of Dolado et al. (2004) reported in column (3), suggesting that all series do not show structural breaks. Therefore, in the following empirical analysis, we model all the series as pure long memory processes. Further support for this modelling choice is provided by other results in the paper, pointing to misspecification in the candidate break-free processes, and suggesting that, in any case, the econometric methodology employed in the following sub-sections is robust to possibly neglected structural changes. ${ }^{7}$

Additional support for the finding of long memory is provided by the semiparametric analysis carried out on the data sampled at the quarterly frequency. Following the Monte Carlo results reported in Morana (2004b), we employed the estimator of the fractional differencing parameter, $d_{R, Q}$, proposed by Robinson (1998). ${ }^{8}$ As shown in column (8) of Table 1, there is

\footnotetext{
${ }^{6}$ The $p$-values for the $L R$ test are computed as in Davies (1987) to account for the non-standard asymptotic distribution of the test.

${ }^{7}$ The finding of no structural change in US inflation contrasts with recent evidence of both long memory and structural change or both structural change and unit root behaviour provided by Bos, Franses and Ooms (1999) and Cook (2005), respectively, who employ monthly data. The analysis of quarterly data also partially contrasts with what obtained using the annual data. In fact, the Kokoszka and Leipus (2000) test points to signficant structural breaks in the nominal variables but not in the real variables, while the augmented Engle and Kozicki test points to a spurious break process for output only. On the other hand, the Dolado, Gonzalo and Mayoral (2004) test points to spurious structural change for all series. A possible explanation for these findings is that results may be sensitive to the frequency of sampling, and that more reliable conclusions may be drawn from lower frequency data, being structural change associated with infrequent changes in the level of the series.

${ }^{8}$ Standard errors have been computed assuming that the same asymptotic distribution holding under weak dependence holds also in the case of long memory, i.e $\sqrt{m}\left(\hat{d}_{R, Q}-d_{R, Q}\right) \stackrel{d}{\longrightarrow} N\left(0, \frac{1}{4}\right)$, where $m$ denotes the bandwidth.
} 
strong evidence of long memory, with estimates of $d_{R, Q}$ in the stable region ranging between 0.21 to 0.33 . It is interesting to note the similar persistence shown by real money growth and output growth on the one hand, and nominal money growth and inflation on the other. According to the one-sided Robinson and Yajima (2002) test for the equality of the fractional differencing parameters (reported in Table 2, Panel A), it is not possible to reject the hypothesis that the series share the same order of fractional integration at the $5 \%$ significance level. ${ }^{9}$ Overall, these results are consistent with the relationships postulated by the quantity theory, since the equality of the fractional differencing parameter is a necessary, yet not sufficient, condition for fractional cointegration between output growth and real money growth, and the latter condition implies (and is implied by) fractional cointegration between inflation and excess nominal money growth. ${ }^{10}$

Finally, since the above results may be affected by an unstable conditional mean and unconditional variance, we have also tested for parameter stability by means of the Nyblom (1989) test. No sign of instability has been detected in any of the parameters for both the inflation and excess nominal money growth processes. ${ }^{11}$ This finding also accords well with the evidence of a high and stable degree of persistence in US inflation recently provided by Pivetta and Reis (2004) for the 1965-2001 period.

\subsection{Fractional cointegration properties}

The existence of long-run linkages among the various processes has been investigated by means of the Robinson and Yajima (2002) fractional cointegrating rank test. The investigated linkages are those postulated by quantity theory, stated in terms of the relationship between inflation and excess nominal money growth, and between real money growth and output growth. Since the Robinson and Yajima (2002) test is subject to arbitrariness in the selec-

\footnotetext{
${ }^{9}$ The analysis has been carried out also using monthly data, since the temporal aggregation properties of long memory processes warrant that the persistence features of the series are unaffected by the frequency of sampling. The monthly dataset counts 533 observations, a sample size which allows for efficient estimation of the fractional differencing parameter. The results (available from the authors upon request) are fully consistent with those obtained using quarterly data.

${ }^{10}$ In order to investigate the impact of possibly neglected structural change on the performance of the estimator, a Monte Carlo exercise has been carried out. This exercise aims to evaluate the consequences of neglecting a break process, as the one detected by the Markov switching model, for the inflation series. The results (available from the authors upon request) suggest that the estimator is not affected by a neglected break process.

${ }^{11}$ The test has been performed in the framework of an ARFIMA-GARCH model. The results are available from the authors upon request.
} 
tion of the critical value (the rule suggested by the authors is the selection of a critical value equal to $0.1 \cdot r / p$, where $r$ is the cointegrating rank and $p$ is the number of processes), conclusions on the existence of cointegration have been drawn also on the basis of the proportion of explained variance associated with each eigenvalue of the spectral matrix in the neighborhood of the zero frequency for the involved processes. If two processes are fractionally cointegrated, then only one eigenvalue should be different from zero, and it should explain the totality of the variance of the series. Panel B of Table 2 reports the proportion of variance explained by the largest eigenvalues $\left(e_{1}\right)$ with the results of the Robinson-Yajima test for a bandwidth of two ordinates, and Figure 3 plots $e_{1}$ for bandwidths up to twenty ordinates. The analysis detects strong evidence of fractional cointegration between real money growth and output growth, since the largest eigenvalue explains almost all of the variance in correspondence of a bandwidths close to the zero frequency (99\% at a bandwidth of two periodogram ordinates) and, as shown in Figure 3, such proportion exceeds $90 \%$ for bandwidths up to nine periodogram ordinates. On the contrary, the analysis of inflation and the excess money growth points to rejection of the null of fractional cointegration, with values of $e_{1}$ quickly falling from $92 \%$ (two ordinates) to $79 \%$ (nine ordinates). These apparently conflicting results may be reconciled by the Monte Carlo results reported in Morana (2004a), pointing to the existence of a downward bias affecting the estimates of $e_{1}$ obtained from the inflation and excess money growth series. The bias is possibly due to the endogeneity of nominal money growth and therefore to the presence of a negative correlation between the regressor and the cointegrating residuals, leading to a downward bias in the estimated cointegrated parameter, the unitary squared coherence at the zero frequency, and the proportion of variance explained by the largest eigenvalue. ${ }^{12}$

The cointegration relationships linking real money growth and output

\footnotetext{
${ }^{12} \mathrm{~A}$ current debate in monetary economics concerns the implications of monetary policy regimes on the endogeneity of the inflation and money growth rates. According to Svensson (2003), nominal money growth would be exogenous relatively to inflation under strict money growth targeting, while inflation would be exogenous relatively to nominal money growth under strict inflation targeting. However, as argued by Nelson (2003), even when money is not used as a policy instrument, monetary policy decisions have an impact on money growth dynamics. For instance, an open market operation which increases the policy rate aiming at a given level of inflation will slow money growth by reducing directly the monetary base. Hence, also in this latter case money growth can be regarded as "quantity-side" indicator of monetary conditions. Then, what explains the final impact on inflation is only a matter of the transmission mechanism. Hence, since we do not aim at investigating the features of the transmission mechanism from the chosen monetary policy instrument to output and eventually inflation, our analysis is valid independently of the monetary policy regime.
} 
growth, and inflation and excess nominal money growth, have been estimated following the approach described in the preceding methodological section. ${ }^{13}$ Results are reported for both pairs of variables in Panel $\mathrm{C}$ of Table 2. The estimated output elasticity of real money balances is consistent with the predictions of quantity theory. The bias-corrected estimates range between 0.98 and 1.14 for bandwidths in the stable region closest to the zero frequency (five-fifteen ordinates), being equal to 0.98 in correspondence of the selected bandwidth (five ordinates). Consistent with this result, we impose the restriction of a $(1,-1)$ cointegrating vector between $r m(\equiv m-\pi)$ and $y$ suggested by the quantity-theory framework outlined in Section 2. The estimated cointegrating relation can then be rewritten in terms of inflation and excess nominal money growth $\mathrm{em}(\equiv m-y)$, implying a unitary coefficient on the latter variable. This prediction, assessed by the direct estimation of the cointegrating relation between $\pi$ and $\mathrm{em}$, finds confirmation in the data: the bias-corrected estimated cointegrating parameter is in the range 1.09-1.18, and equal to 1.09 in correspondence of the selected bandwidth (two ordinates). ${ }^{14}$ When the $(1,-1)$ restriction is imposed on the long-run parameters, the resulting estimates of the loading vector $\Theta$ are reported in Panel 3 of Table 2 for both pairs of variables. Those restricted estimates are then used in the following sub-section to finally compute our proposed measure for the long-run monetary inflation rate.

\subsection{Computing and evaluating the long-run monetary inflation process}

Estimation of the fractional cointegration parameters in $\boldsymbol{\beta}$ and of the associated factor loading coefficients in $\Theta$ allow for the computation of the persistent, long-memory, component of the inflation rate, $\pi_{t}^{*}$, which, according to (8), is given by $\pi_{t}^{*}=\hat{\mu}_{l m, t}^{n}+\hat{\mu}_{l m, t}^{r} \equiv \hat{\mu}_{l m, t}$. This process captures the common persistent element of inflation and excess money growth, consistent

\footnotetext{
${ }^{13}$ To evaluate robustness, the persistence and cointegration properties have been also evaluated for the $M 1$ and $M 2$ monetary aggregates, yielding similar results, available from the authors upon request. Overall, the findings suggest that the long-run linkages are stronger for $M 3$.

${ }^{14}$ As a further robustness check we have carried out a Monte Carlo experiment to evaluate the impact of a neglected break process, as the one detected by the Markov switching moodel for inflation, on the performance of the estimator. The results suggest that the estimator is robust to neglected breaks, and are available from the authors upon request. Moreover, the estimation of the cointegration relationship has also been carried out on the candidate break-free inflation and excess nominal money growth processes. The evidence is against the break-free processes: in fact, the estimated parameter points to a negative long-run relationship between the two series, suggesting misspecification.
} 
with the (estimated and tested) long-run cointegration features of the series.

Figure 4 plots the long-run "monetary" inflation process $\pi_{t}^{*}$ together with the observed inflation rate $\pi_{t}$ from 1960(1) up to 2003(2). The series are shown as 4-quarter (upper panel) and 12-quarter (lower panel) moving averages of the quarterly rate to highlight their medium- to long-term behavior. The difference between the two series, $\pi_{t}-\pi_{t}^{*}$, represents the non-persistent (short-run) inflation component. As can be seen from the plots, until the late 1980s the observed inflation rate is more closely linked to the long-run monetary inflation rate than in the later part of the period, where the nonpersistent inflation component gains importance. Several particular episodes are worth mentioning. The inflation spike of 1979-80, corresponding to the second major oil price shock of the seventies, is not entirely mirrored by the long-run inflation measure, leaving a sizeable short-run component. A different pattern emerges for the first oil price shock of 1973-75, when the long-run inflation measure signalled a relatively high inflation potential already in 1971-72, as a result of the generous growth of monetary aggregates, whereas observed inflation was relatively low (also as a consequence of the price controls imposed in 1971 and removed in 1973-74). Though to a lesser extent than in the 1979 episode, also the oil price counter-shock of 1986 had a transitory effect on inflation, signalled by long-run inflation this time higher than the observed rate. The sharp decrease of monetary growth in the first half of the 1990s is reflected in the long-run inflation measure, which dropped around zero in 1992-94. The following quick upsurge of monetary growth in the second half of the decade again drove upwards the long-run inflation measure, which started lying above observed inflation from 1998, though the gap is closing over the last year of the sample.

Figure 5 shows a comparison between the long-run inflation rate $\pi^{*}$ and two "core inflation" measures, widely used to remove transient elements from the observed inflation rate and capture its long-run trend. Both measures feature prominently in commentaries and assessments of the monetary policy stance. The first is the "ex food and energy" series, which removes food and energy items from the basket of goods used to compute the inflation rate. The reason is that food and energy prices are viewed as highly volatile series, dominated by high-frequency, transitory movements mainly unrelated to long-run inflation determinants. The second popular measure of core inflation is the (weighted) median inflation rate proposed by Bryan and Cecchetti (1994), which captures the central tendency of the cross-sectional distribution of price changes with no need to select (and exclude from computation) a priori the most volatile prices. In proposing this measure, the explicit aim of Bryan and Cecchetti (1994) is the extraction of "a measure of moneyinduced inflation: that is, the component of price changes that is expected 
to persist over medium-run horizons of several years" (p. 197). It seems therefore interesting to compare the behavior of this series with a long-run "monetary" inflation rate explicitly derived from the common persistent element in the observed inflation and (excess) monetary growth series. Figure 5 shows that the ex-food and energy and median inflation series are relatively close to each other over the whole sample, and differ sizably from the long-run "monetary" inflation measure $\pi^{*}$. Moreover, they track observed inflation much more closely than $\pi^{*}$, also in the period starting around the late 1980s when the latter series displays a very different behavior, as shown in Figure 4. This evidence suggests that the proposed long-run inflation rate, though sharing the same motivation as some popular core inflation series, does capture information not contained in the ex-food and energy and median inflation measures of the inflation trend.

To further evaluate the properties of the long-run inflation rate $\pi^{*}$ we investigate whether deviations of observed inflation from the long-run measure, reflecting the purely transient inflation component, predict future inflation changes at various horizons. If such deviations effectively capture transient inflation movements, they should be negatively related to subsequent inflation changes in the following regression

$$
\pi_{t+h}-\pi_{t}=\gamma_{0}+\gamma_{1}\left(\pi_{t}-\pi_{t}^{*}\right)+\eta_{t+h},
$$

where $h$ denotes the chosen horizon. The estimated coefficients from (17) at different horizons, ranging from 2 up to 12 quarters, are reported in Table 3. Estimates of $\gamma_{1}$ are negative and strongly statistically significant at all horizons. The magnitude of the coefficient increases as the horizon lengthens, attaining -0.52 and -0.66 for the 8- and 12-quarter horizons respectively. Therefore, current observed inflation above the long-run measure predict subsequent reductions in the inflation rate, and more strongly so over the two- to three-year horizon, broadly corresponding to the focus of forwardlooking monetary policy.

A more compelling evaluation of the proposed measure could come from an out-of-sample forecasting analysis, especially over medium-run horizons, although for samples of our size there is not a large number of non-overlapping intervals. With this caveat in mind, we nevertheless carried out a forecasting exercise, comparing the forecasting performances of $\pi^{*}$ and three competing models aimed to capture the long-run inflation trend. In particular, we analyzed a simple ARFIMA model fitted to observed inflation data, the already mentioned Bryan-Cecchetti median inflation rate (forecasted by means of an ARFIMA model), and the series obtained by applying a simple exponential smoothing $(E S)$ to observed inflation data. The latter measure has been recently proposed by Cogley (2002) as a simple and effective way of capturing 
persistent changes in inflation, particularly those related to changes in the monetary policy regime. The theoretical underpinning for this measure can be found in the analysis of the US inflation process in Sargent (1999) and Cogley and Sargent (2001).

We carried out our exercise over five forecasting horizons, ranging from 2 to 12 quarters, and for both a 4-quarter moving average and a 12-quarter centered moving average of the quarterly inflation rate. The models have been estimated recursively with forecasts generated over the 1990(2)-2003(2) period. The results are collected in Table 4: the upper part of both panels reports root mean square forecast errors $(R M S E)$ and the lower part shows the $p$-values of the West and Cho (1995) test for the equality of the $R M S E$ obtained from $\pi^{*}$ and each of the competing measures in turn.

Several results are worth mentioning. In the comparison with the univariate time-series ARFIMA model, the long-run inflation rate $\pi^{*}$ shows in both panels a superior forecasting performance starting for horizons longer than one year; the results of the West-Cho tests confirm that the differences of the RMSEs are statistically significant. When compared with the BryanCecchetti median inflation rate, $\pi^{*}$ fares better than the competing measure over forecasting horizons longer than two quarters in panel A and over all horizons in panel B (in this latter case at the $10 \%$ significance level for the 2 - and 4-quarter horizons). Finally, $\pi^{*}$ has a marginally better (but not significantly so) forecasting performance than the Cogley (2002) ES series only over horizons of 6 and 8 quarters in panel B.

Overall, the results of the forecasting exercise suggest that extracting a long-run measure of the inflation rate from the common long-memory component of inflation and money growth may be useful for forecasting especially over the two- to three-year horizons, which are the most relevant for monetary policy purposes. This finding is coherent also with the available evidence for the Euro area (Morana, 2005a).

\section{Conclusions}

Recent developments in macroeconomic theory and monetary policy practice have downplayed the role of monetary aggregates. For example, NewKeynesian models incorporated policy rules setting short-term interest rates with no explicit money terms, and the adoption of direct inflation targeting by policymakers in several countries contributed to shift attention away from monetary aggregates. However, the existence of a long-run link between inflation and money growth is still widely believed by theorists and policymakers, despite some recent challenging evidence (Nelson 2003, De Grauwe 
and Polan 2001).

In this paper we studied the link between inflation and money growth in the US over the 1960-2003 period, adopting the quantity theory as a general framework relating inflation to the growth rates of nominal money aggregates and real output in the long run. The common persistence properties of the variables, modelled as fractionally integrated and cointegrated series, have been exploited to construct a measure of the long-run inflation trend closely linked to monetary dynamics, using principal components techniques in the frequency domain. The resulting series therefore captures the long-run inflationary potential embodied in current money and output growth rates.

As such, the estimated "monetary" inflation rate could provide useful information to inflation-targeting monetary policymakers interested in having timely indicators of future inflation developments over the relevant mediumterm horizon of two to three years. When directly compared with currently used measures of "core inflation" (such as the median inflation rate) claiming to capture the long-run inflation trend ultimately linked to money growth, the measure estimated in this paper performs acceptably well in out-of-sample forecasting exercises over the horizons most relevant for monetary policy purposes.

Overall, the long-run inflation measure proposed in this paper, derived by taking into proper account the common persistence features of inflation and money growth, lends some support to the view that monetary aggregates can still provide valuable information to monetary policymakers.

\section{References}

[1] Ang, A. and G. Bekaert (2002), Regime Switches in Interest Rates, Journal of Business and Economic Statistics, 20, 163-182.

[2] Bagliano, F. and C. Morana (2003), Measuring US Core Inflation, Journal of Macroeconomics, 25, 197-212.

[3] Bagliano F.C., R. Golinelli and C. Morana (2002), Core Inflation in the Euro Area, Applied Economics Letters, 9, 353-357.

[4] Bagliano F.C., R. Golinelli and C. Morana (2003), Inflation Modelling in the Euro Area, in Fiscal Policies, Monetary Policies and Labour Markets. Key Aspects of European Macroeconomic Policies after Monetary Unification, R. Beetsma, C. Favero, A. Missale, V.A. Muscatelli, P. Natale e P. Tirelli (eds), Cambridge University Press. 
[5] Batini N. and E. Nelson (2001), The Lag from Monetary Policy Actions to Inflation: Friedman Revisited, International Finance, 4, 381-400.

[6] Begg D., F. Canova, A. Fatas, P. De Grauwe and P.R. Lane (2002), Surviving the Slowdown, Monitoring the European Central Bank. vol. 4, CEPR.

[7] Beltratti, A. and C. Morana (2005), Breaks and Persistency: Macroeconomic Causes of Stock Market Volatility, Journal of Econometrics, forthcoming.

[8] Bos, C.S., P.H. Franses and M. Ooms (1999), Long Memory and Level Shifts: Re-Analyzing Inflation Rates, Empirical Economics, 24, 427-49.

[9] Bos, C.S., P.H. Franses and M. Ooms (2002), Inflation, Forecast Intervals, and Long Memory Regression Models, International Journal of Forecasting, 18, 243-264.

[10] Bryan, M.F. and S.G. Cecchetti (1993), The Consumer Price Index as a Measure of Inflation, Federal Reserve Bank of Cleveland Economic Review, 15-24.

[11] Bryan, M.F. and S.G. Cecchetti (1994), Measuring Core Inflation, in N.G. Mankiw, ed., Monetary Policy, 195-215, NBER, University if Chicago Press.

[12] Cecchetti S.G. (1997), Measuring Long-Run Inflation for Central Bankers, Federal Reserve of St. Louis Economic Review, 79, 143-155.

[13] Chen, W.W. and C.H. Hurvich (2002), Semiparametric Estimation of Multivariate Fractional Cointegration, Journal of the American Statistical Association, forthcoming.

[14] Cogley T. (2002), A Simple Adaptive Measure of Core Inflation, Journal of Money, Credit and Banking, 34, 94-113.

[15] Cogley T. and T.J. Sargent (2001), Evolving Post-World War II U.S. Inflation, NBER Macroeconomics Annual 2001, MIT Press, 331-372.

[16] Cook S. (2005), Rank-Based Unit Root Testing in the Presence of Structural Change Under the Null: Simulation Results and an Application to US Inflation, Applied Economics, 37, 607-17.

[17] Davies, R.B. (1987),. Hypothesis Testing when a Nuisance Parameter is Present only Under the Alternative, Biometrika, 74(1), 33-43. 
[18] De Grauwe P. and M. Polan (2001), Is Inflation Always and Everywhere a Monetary Phenomenon?, CEPR discussion paper 2841.

[19] Diebold F.X. and A. Inoue (2001), Long memory and regime shifts, Journal of Econometrics, 105, 131-159.

[20] Dolado J., J. Gonzalo and L. Mayoral (2004), A Simple Test of Long Memory vs. Structural Breaks in the Time Domain: What is What?, mimeo, Universidad Carlos III de Madrid.

[21] Engle, R.F. and S. Kozicki (1993), Testing for Common Features, Journal of Business and Economic Statistics, 11(4), 369-80.

[22] Friedman M. (1963), Inflation: Causes and Consequences, Asia Publishing House, New York.

[23] Friedman M. (1992), Money Mischief, Harcourt Brace Jovanovich, New York.

[24] Gerlach S. and L.E.O. Svensson (2003), Money and inflation in the euro area: A case for monetary indicators?, Journal of Monetary Economics, $50,1649-1672$.

[25] Granger, C.W.J. and N. Hyung (2004), "Occasional structural breaks and long memory with an application to the S\&P 500 absolute stock returns, Journal of Empirical Finance, 11, 399-421.

[26] Hallman J.J., R.D. Porter and D.H. Small (1991), Is the price level tied to the M2 monetary aggregate in the long-run?, American Economic Review, 81, 841-858.

[27] Hamilton, J.D. (1990), Analysis of Time Series Subject to Changes in Regime, Journal of Econometrics, 45, 39-70.

[28] Hassler, U. and J. Wolters (1995), Long Memory in Inflation Rates: International Evidence, Journal of Business and Economic Statistics, $13,1$.

[29] Hyung N., P.H. Franses and J. Penm (2004), Structural Breaks and Long Memory in US Inflation Rates: Do They Matter for Forecasting?, mimeo, http://ssrn.com/abstract $=506323$.

[30] Kasa, K. (1992), Common Stochastic Trends in International Stock Markets, Journal of Monetary Economics, 29, 95-124. 
[31] Kokoszka, P. and R. Leipus (2000), Change Point Estimation in ARCH Models, Bernoulli, 6, 1-28.

[32] Leeper E.M. and J.E. Roush (2003), Putting 'M' Back in Monetary Policy, Journal of Money, Credit and Banking, 35, 1217-1256.

[33] Lucas R.J. Jr. (1996), Nobel lecture: Monetary neutrality, Journal of Political Economy, 104, 661-682.

[34] McCallum B.T. (2001), Monetary policy analysis in models without money, Federal Reserve Bank of St. Louis Economic Review, 83, 145-160.

[35] McCandless G.T. Jr. and W.E. Weber (1995), Some monetary facts, Federal Reserve Bank of Minneapolis Quarterly Review, 19, 2-11.

[36] Morana, C. (2002), Common Persistent Factors in Inflation and Excess Nominal Money Growth and a New Measure of Core Inflation, Studies in Non Linear Dynamics and Econometrics, 6(3), art.3, art.5.

[37] Morana, C. (2004a), Frequency Domain Principal Components Estimation of Fractionally Cointegrated Long Memory Processes, Applied Economics Letters, 11, 837-42.

[38] Morana, C. (2004b), A Structural Common Factor Approach to Core Inflation Estimation and Forecasting, ECB Working Paper Series no.305.

[39] Morana, C. (2005a), A Structural Common Factor Approach to Core Inflation Estimation and Forecasting, Applied Economics Letters, 2005, forthcoming.

[40] Morana, C. (2005b), Frequency Domain Principal Components Estimation of Fractionally Cointegrated Processes: Some New Results and an Application to Stock Market Volatility, Physica A, forthcoming.

[41] Morana, C. and A. Beltratti (2004), Structural Change and Long Range Dependence in Volatility of Exchange Rates: Either, Neither or Both?, Journal of Empirical Finance, 11, 629-58.

[42] Nelson E. (2003), The future of monetary policy aggregates in monetary policy analysis, Journal of Monetary Economics, 50, 1029-1059.

[43] Nyblom, J. (1989), Testing for the constancy of parameters over time, Journal of the American Staistical Association, 84(405), 223-30. 
[44] Pivetta F. and R. Reis (2004), The Persistence of Inflation in the United States, mimeo, Harvard University.

[45] Quah D. and S. Vahey (1995), Measuring Core Inflation, Economic Journal, 130, 1130-1144.

[46] Robinson, P.M. (1998), Comment, Journal of Business and Economic Statistics, 16(3), 276-79.

[47] Robinson, P.M. and Y. Yajima (2002), Determination of Cointegrating Rank in Fractional Systems, Journal of Econometrics, 106(2), 217-41.

[48] Robinson, P.M. and D. Marinucci (2001), Semiparametric fractional cointegration analysis, Journal of Econometrics, 105, 225-247.

[49] Sargent, T.J. (1999), The Conquest of American Inflation, Princeton: Princeton University Press.

[50] Svensson L.E.O. (2002), A reform of the Eurosystem's monetary-policy strategy is increasing urgent, Briefing paper for the Committee on Economic and Monetary Affairs, European Parliament.

[51] Svensson L.E.O. (2003), "Comment on: The future of monetary aggregates in monetary policy analysis", Journal of Monetary Economics, 50, 1061-1070.

[52] Taylor J.B. (ed.) (1999), Monetary policy rules, Chicago, University of Chicago Press.

[53] Walsh C.E. (2003), Monetary Theory and Policy, second edition, Cambridge, MIT Press.

[54] West K. and D. Cho (1995), The predictive ability of several models of exchange rate volatility, Journal of Econometrics, 69, 367-391. 
Table 1

Structural change and persistence analysis

\begin{tabular}{c|ccc|ccc|c|c}
\hline \hline & $\begin{array}{c}(1) \\
K L_{.2}\end{array}$ & $K L_{.4}$ & $D G M$ & $B I C_{1}$ & $B I C_{2}$ & $L R$ & $\begin{array}{c}(7) \\
d_{E K, Y}\end{array}$ & $d_{R, Q}$ \\
\hline$\pi$ & 0.711 & 0.994 & 0.918 & 5.122 & 4.626 & 0.000 & $\begin{array}{c}-0.185 \\
(0.310)\end{array}$ & $\begin{array}{c}0.326 \\
(0.091)\end{array}$ \\
\hline$m$ & 0.797 & 1.006 & 0.743 & 5.434 & 5.186 & 0.000 & $\begin{array}{c}0.231 \\
(0.144)\end{array}$ & $\begin{array}{c}0.306 \\
(0.104)\end{array}$ \\
\hline$e m$ & 0.873 & 1.149 & -0.797 & 5.601 & 5.860 & 0.015 & $\begin{array}{c}-0.698 \\
(0.266)\end{array}$ & $\begin{array}{c}0.277 \\
(0.095)\end{array}$ \\
\hline$r m$ & 0.667 & 0.980 & 0.392 & 5.771 & 5.699 & 0.002 & $\begin{array}{c}-0.027 \\
(0.170)\end{array}$ & $\begin{array}{c}0.256 \\
(0.073)\end{array}$ \\
\hline$y$ & 0.813 & 0.933 & -0.846 & 4.651 & 4.826 & 0.289 & $\begin{array}{c}0.059 \\
(0.130)\end{array}$ & $\begin{array}{c}0.211 \\
(0.112)\end{array}$ \\
\hline \hline
\end{tabular}

Note: Columns (1 ) and (2) report the values of the Kokoszka-Leipus (2000) test $(K L)$ for the no-break hypothesis (critical values of the test are 1.22, 1.36, 1.63 at the $10 \%, 5 \%$, and $1 \%$ respectively). Column (3) report the value of the Dolado, Gonzalo and Mayoral (2004) test $(D G M)$ fror the null of pure long memory process (critical values of the test are $-1.64,-2.00,1.99$ at the $10 \%, 5 \%$, and $1 \%$ respectively). Columns (4) and (5) show the values of the Bayes-Schwartz information criterion for the linear (constant mean) model $\left(B I C_{1}\right)$ and the two-regime Markovswitching model $\left(B I C_{2}\right)$. The $p$-value of the likelihood ratio test $(L R)$, computed as in Davies (1987), for the null of a constant-mean model is reported in column (6). Column (7) presents the fractional differencing parameter obtained from the augmented Engle and Kozicki (1993) ARFIMA regression $\left(d_{E K, Y}\right)$. Column (8) shows the semiparametric estimates of the fractional differencing parameter obtained from the estimator proposed by Robinson (1998) applied to quarterly data $\left(d_{R, Q}\right)$. In columns $(7)$ and (8) standard errors are in parentheses. The series are defined as: CPI inflation rate $(\pi)$, nominal $M 3$ growth rate $(m)$, real $M 3$ growth rate $(\mathrm{rm})$, real GDP growth rate $(y)$, excess nominal $M 3$ growth rate $(\mathrm{em})$. Tests in columns (1) to (7) are carried out on annual data from 1959 to 2002. The $d_{R, Q}$, test in column (8) uses quarterly data from 1959(1) to 2003(2). 


\section{Table 2}

Panel A: Test for the equality of the fractional differencing parameters

\begin{tabular}{c|ccc}
\hline \hline \multicolumn{4}{|c}{ Quarterly data } \\
\hline & $\pi$ & $\mathrm{em}$ & $\mathrm{rm}$ \\
$\mathrm{em}$ & 0.355 & & \\
$\mathrm{rm}$ & 0.428 & 0.432 & \\
$y$ & 0.208 & 0.324 & 0.278 \\
\hline \hline
\end{tabular}

Panel B: Fractional cointegrating rank test (quarterly data)

\begin{tabular}{c|cc||l|cc}
\hline \hline$\pi /$ em & $e_{1}$ & 0.922 & & $e_{1}$ & 0.999 \\
& $99 \%$ & 0.197 & $r m / y$ & $99 \%$ & $1 \mathrm{e}-04$ \\
& $95 \%$ & 0.162 & & $95 \%$ & $1 \mathrm{e}-04$ \\
& $s$ & 2 & & $s$ & 2 \\
\hline \hline
\end{tabular}

Panel C: Long-run parameter estimates (quarterly data)

\begin{tabular}{c|ccc}
\hline \hline & $\boldsymbol{\beta}$ unrestr. & $\boldsymbol{\beta}$ restr. & $\Theta$ \\
\hline$\pi$ & 1 & 1 & 1.363 \\
& & & $(0.011)$ \\
$\mathrm{e} m$ & -1.091 & -1 & 1.363 \\
& $(0.006)$ & & $(0.011)$ \\
\hline \hline & $\boldsymbol{\beta}$ unrestr. & $\boldsymbol{\beta}$ restr. & $\Theta$ \\
\cline { 2 - 4 }$r m$ & 1 & 1 & 0.952 \\
& & & $(0.022)$ \\
$y$ & -0.981 & -1 & 0.952 \\
& $(0.021)$ & & $(0.022)$ \\
\hline \hline
\end{tabular}

Notes: Panel A reports the $p$-value of the Robinson and Yajima (2002) one sided test for the equality of the fractional differencing parameter. Panel B reports the results of the Robinson and Yajima (2002) fractional cointegrating rank test. The investigated cointegration relationships involve inflation and excess nominal money growth $(\pi / \mathrm{em})$, and real money growth and output growth $(\mathrm{rm} / \mathrm{y}) \cdot e_{1}$ denotes the proportion of variance explained by the largest eigenvalue, followed by the values of the test for the $99 \%$ and $95 \%$ significance levels; $s$ is the bandwidth used. The null hypothesis of the test is cointegration and the critical value suggested by Robinson and Yajima (2002) is $0.1 / 2=0.05$ for 2 processes and 1 cointegrating vector. Panel $\mathrm{C}$ reports the estimated unrestricted $(u)$ and restricted $(r)$ cointegrating vectors $(\mathrm{CV})$, and the estimated factor loading matrix for the restricted model. Standard errors have been computed using the jack-knife. The series are as follows: CPI inflation rate $(\pi)$, real M3 growth rate $(\mathrm{rm})$, real GDP growth rate $(y)$, excess nominal M3 growth rate $(\mathrm{em})$. 


\section{Table 3}

Non-persistent component as predictor of future inflation changes

\begin{tabular}{cccc}
\hline $\begin{array}{c}\text { Horizon } h \\
\text { (quarters) }\end{array}$ & $\begin{array}{c}\hat{\gamma}_{0} \\
\text { (s.e.) }\end{array}$ & $\begin{array}{c}\hat{\gamma}_{1} \\
\text { (s.e.) }\end{array}$ & $R^{2}$ \\
\hline 2 & 0.003 & -0.214 & 0.05 \\
& $(0.181)$ & $(0.085)$ & \\
4 & 0.022 & -0.222 & 0.04 \\
& $(0.207)$ & $(0.091)$ & \\
6 & 0.038 & -0.292 & 0.06 \\
& $(0.232)$ & $(0.095)$ & \\
8 & 0.045 & -0.518 & 0.13 \\
& $(0.261)$ & $(0.122)$ & \\
12 & 0.165 & -0.658 & 0.17 \\
& $(0.272)$ & $(0.123)$ & \\
\hline \hline
\end{tabular}

Notes: The table reports the estimated coefficients (with associated standard errors) and $R^{2}$ statistics from the following equation:

$$
\pi_{t+h}-\pi_{t}=\gamma_{0}+\gamma_{1}\left(\pi_{t}-\pi_{t}^{*}\right)+\eta_{t+h}
$$

where $h$ is the forecasting horizon (in quarters). Estimation is carried out by OLS with heteroskedasticity and autocorrelation-consistent standard errors. The sample period is 1959(2)-2003(2), with endpoint appropriately adjusted to the forecasting horizon. 


\section{Table 4}

Out-of-sample forecasting analysis

Panel A: Forecast of the 4-quarter moving average of quarterly inflation

\begin{tabular}{cccccc}
\hline \hline & \multicolumn{5}{c}{ Horizon (quarters) } \\
\cline { 2 - 6 } Series & 2 & 4 & 6 & 8 & 12 \\
\hline$\pi^{*}$ & 1.857 & 1.422 & 1.340 & 1.370 & 1.453 \\
ARFIMA & 0.650 & 1.251 & 1.507 & 1.658 & 1.835 \\
$E S$ & 0.807 & 0.964 & 1.069 & 1.128 & 1.138 \\
Median & 1.484 & 1.676 & 1.867 & 1.978 & 2.158 \\
\hline$H_{\text {ARFIMA }}$ & 0.00 & 0.09 & $\mathbf{0 . 0 3}$ & $\mathbf{0 . 0 0}$ & $\mathbf{0 . 0 0}$ \\
$H_{E S}$ & 0.00 & 0.00 & 0.02 & 0.01 & 0.00 \\
$H_{\text {Median }}$ & 0.00 & $\mathbf{0 . 0 1}$ & $\mathbf{0 . 0 0}$ & $\mathbf{0 . 0 0}$ & $\mathbf{0 . 0 0}$ \\
\hline \hline
\end{tabular}

Panel B: Forecast of the 12-quarter moving average of quarterly inflation

\begin{tabular}{cccccc}
\hline \hline & \multicolumn{5}{c}{ Horizon (quarters) } \\
\cline { 2 - 6 } Series & 2 & 4 & 6 & 8 & 12 \\
\hline$\pi^{*}$ & 1.472 & 0.737 & 0.610 & 0.649 & 0.832 \\
ARFIMA & 0.522 & 0.687 & 0.934 & 1.122 & 1.364 \\
$E S$ & 0.440 & 0.531 & 0.632 & 0.712 & 0.769 \\
Median & 1.777 & 1.074 & 1.305 & 1.475 & 1.686 \\
\hline$H_{\text {ARFIMA }}$ & 0.00 & 0.80 & $\mathbf{0 . 0 3}$ & $\mathbf{0 . 0 0}$ & $\mathbf{0 . 0 0}$ \\
$H_{E S}$ & 0.00 & 0.35 & $\mathbf{0 . 9 1}$ & $\mathbf{0 . 7 1}$ & $\mathbf{0 . 6 3}$ \\
$H_{\text {Median }}$ & $\mathbf{0 . 0 6}$ & $\mathbf{0 . 0 8}$ & $\mathbf{0 . 0 0}$ & $\mathbf{0 . 0 0}$ & $\mathbf{0 . 0 0}$ \\
\hline \hline
\end{tabular}

Notes: The table reports the root mean squared error (RMSE, in percentage points) of forecasts of the 4-quarter (Panel A) and 12-quarter (Panel B) moving averages of the quarterly inflation rate, obtained from the estimated $\pi^{*}$ series, from a univariate ARFIMA model of the observed quarterly inflation rate, from the exponentially smoothed inflation series $(E S)$ with a smoothing parameter equal to 0.125 as in Cogley (2002), and from an ARFIMA model applied to the median inflation rate (Median) of Bryan and Cecchetti (1994). Forecasting models are estimated recursively and forecasts are generated over the 1990(2)-2003(2) period with forecasting horizon ranging from 2 to 12 quarters. In both panels, $H_{A R F I M A}$, $H_{E S}$ and $H_{\text {Median }}$ denote the asymptotic p-values of the West-Cho (1995) $\chi^{2}(1)$ test statistic for the null hypothesis of equality between the RMSE of the forecasts from $\pi^{*}$ and from the ARFIMA,ES, and Median series. Cases in which the RMSE from the $\pi^{*}$ series is lower than that of the competing series are highlighted in boldface. 

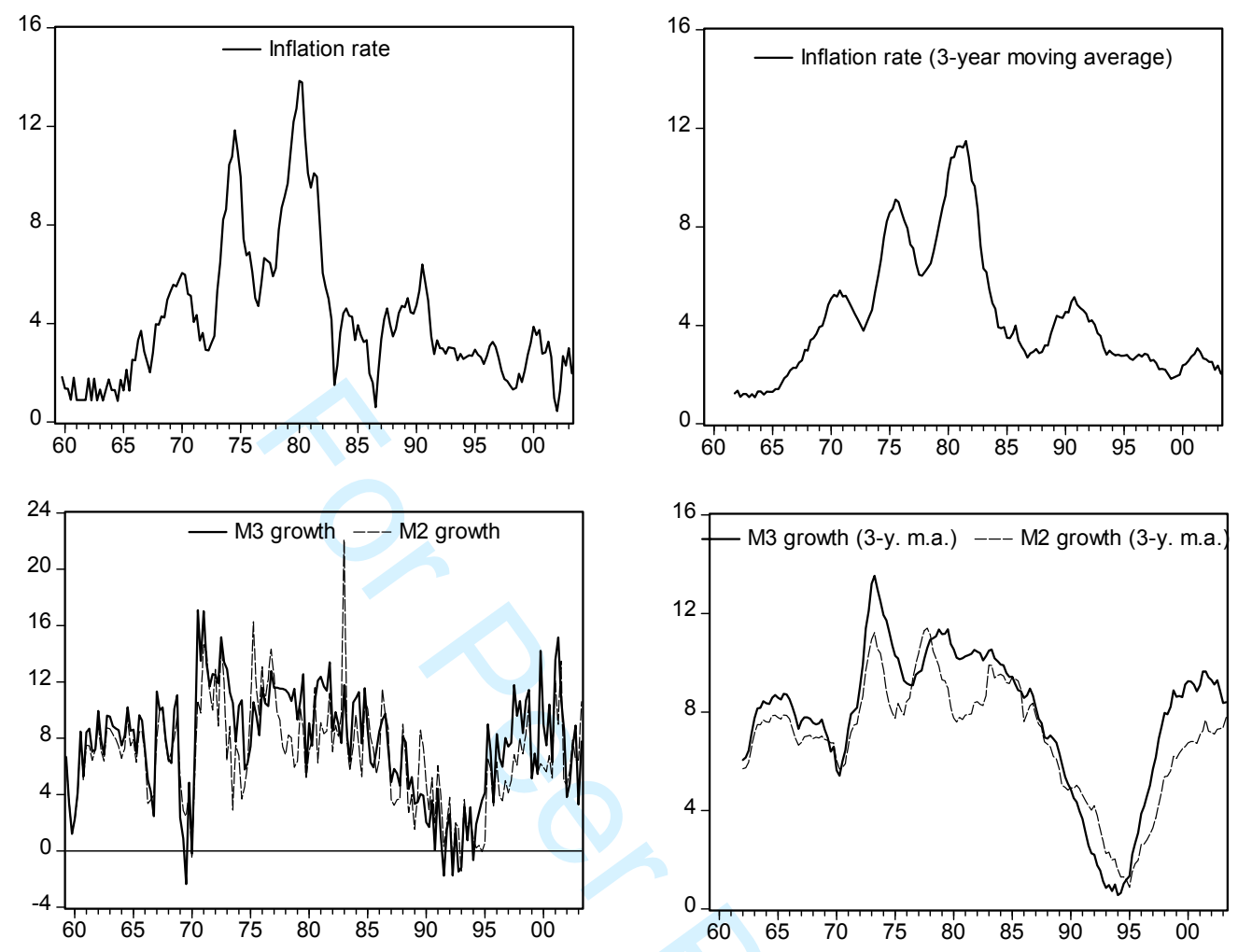

Figure 1. US CPI inflation and money growth. Left-hand panels: quarterly rates, 1959(2)-2003(2). Right-hand panels: 12-quarter backward moving averages of (annualized) quarterly rates, 1962(1)-2003(2). 

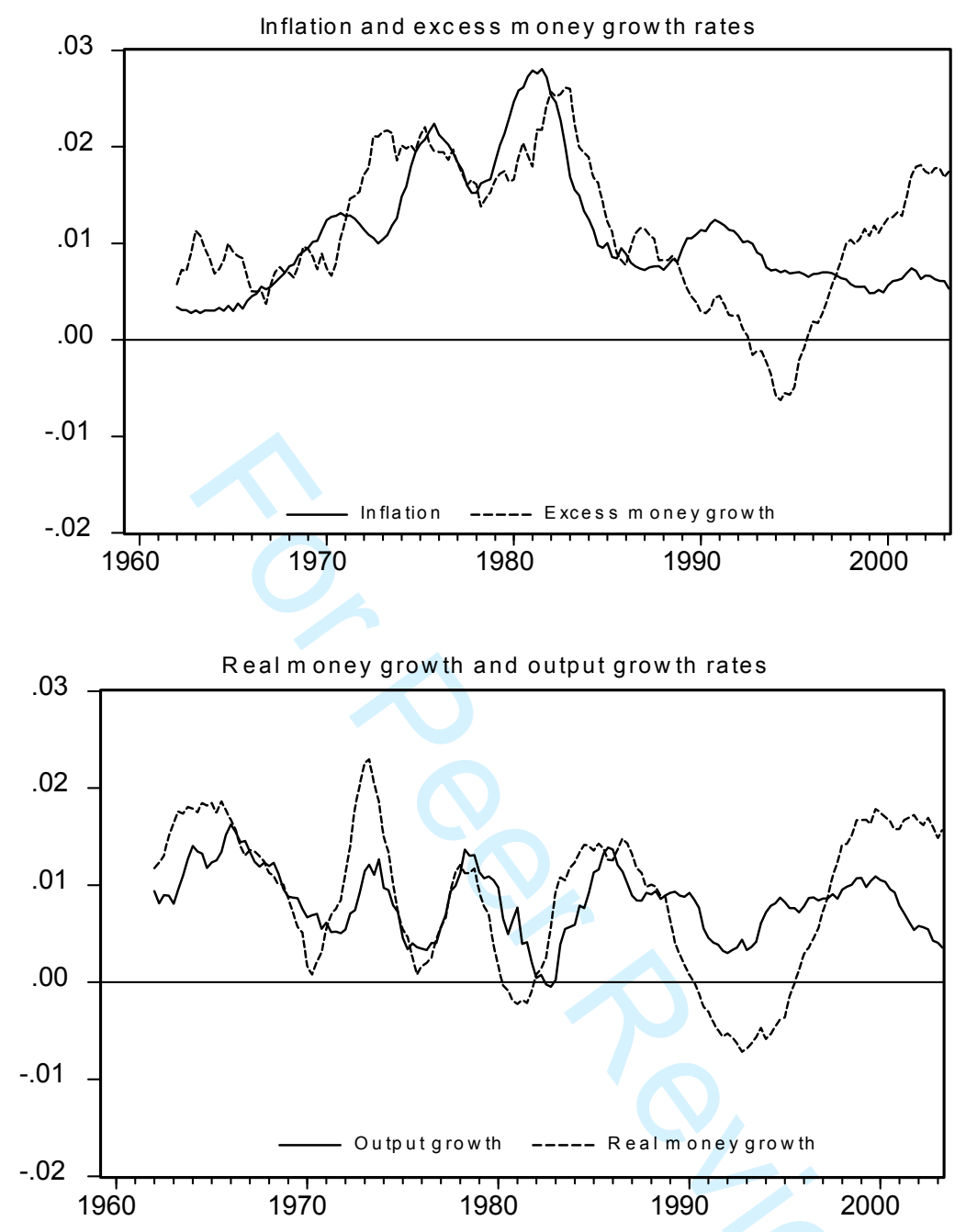

Figure 2. US inflation rate $(\pi)$, excess money growth rate $(\mathrm{em})$, real $M 3$ money growth rate $(\mathrm{rm})$ and output growth rate $(y)$. All series are 12quarter backward moving averages of quarterly rates. The sample period is 1962(1)-2003(2) 


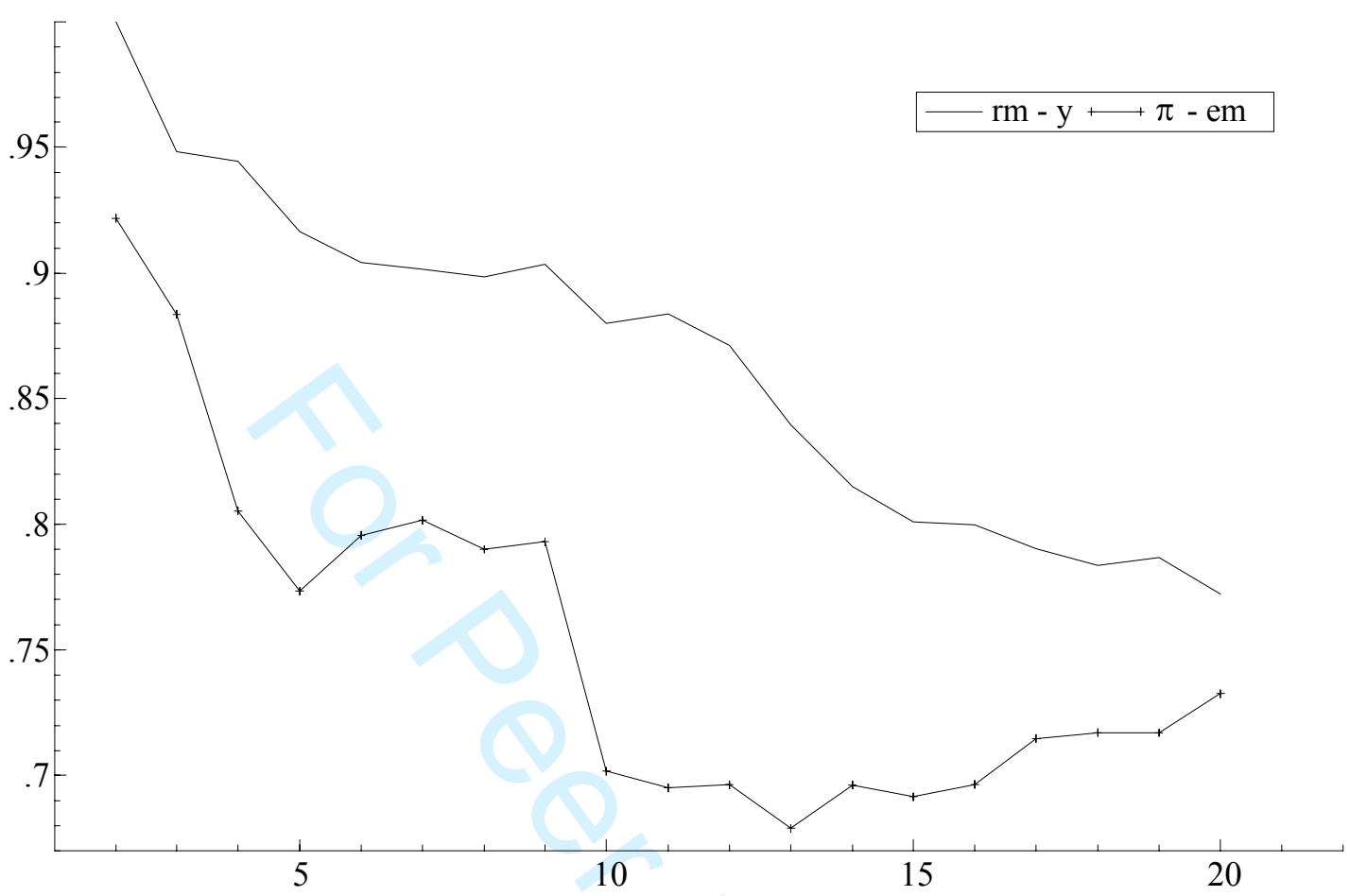

Figure 3.Proportion of variance explained by the largest eigenvalue $\left(e_{1}\right)$ plotted against the bandwidth. The series are: CPI inflation rate $(\pi)$, real $M 3$ growth rate $(\mathrm{rm})$, real GDP growth rate $(\mathrm{g})$, excess nominal $M 3$ growth rate $(\mathrm{em})$. 

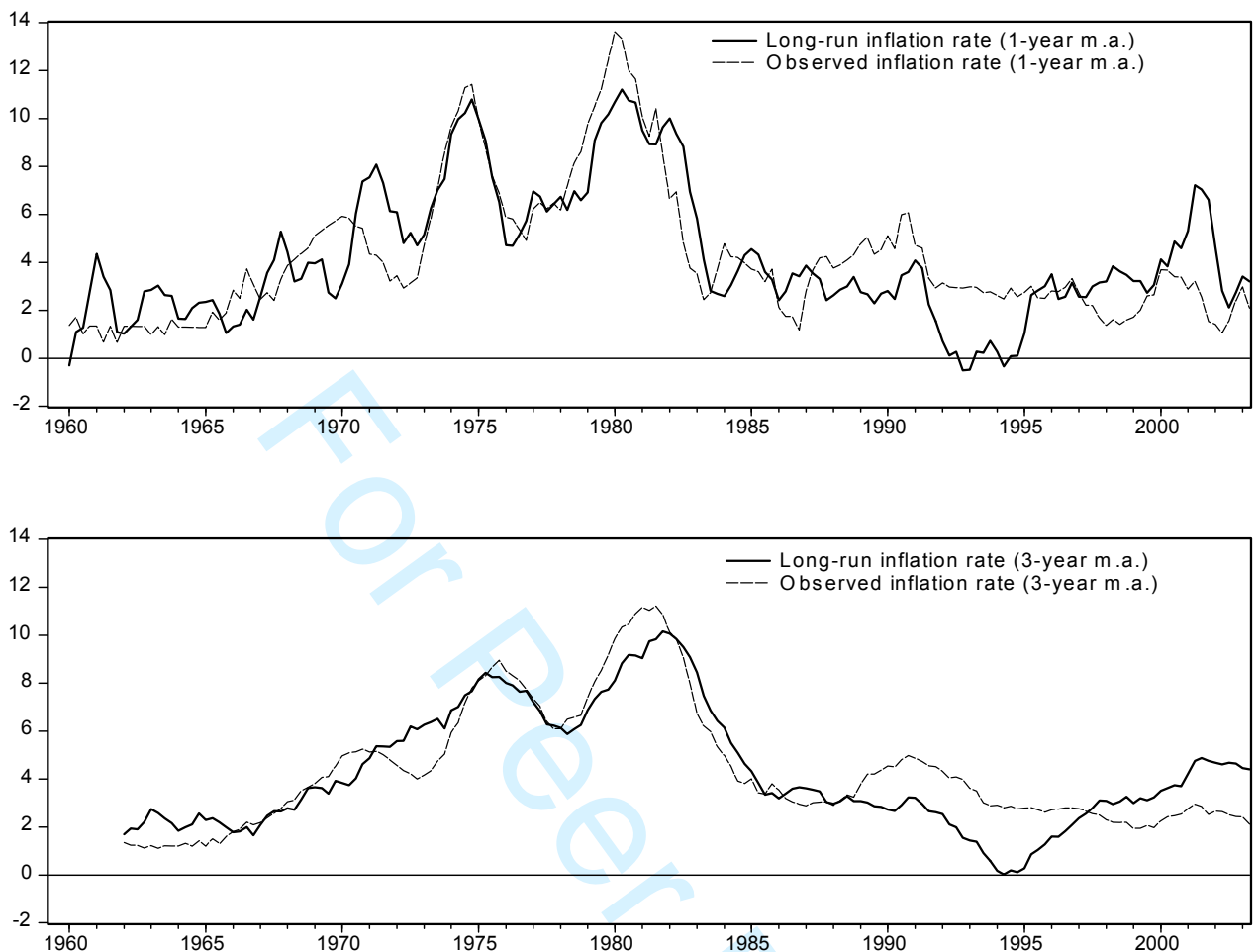

Figure 4. US observed inflation rate $(\pi)$ and estimated long-run "monetary" inflation rate $\left(\pi^{*}\right)$ : 4-quarter (upper panel, 1960(1)-2003(2)) and 12quarter (lower panel, 1962(1)-2003(2)) moving averages of (annualized) quarterly rates. 

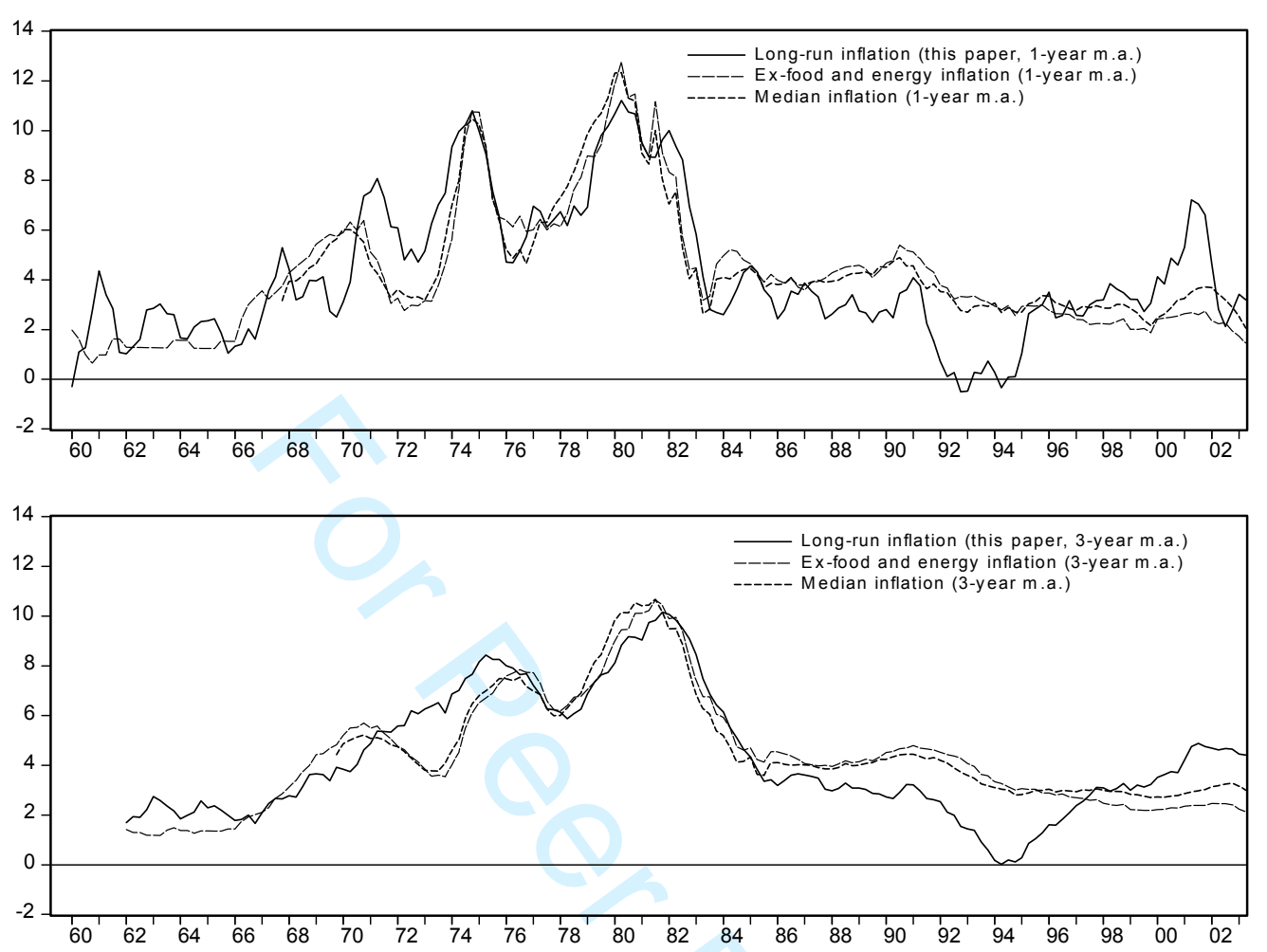

Figure 5. US estimated long-run "monetary" inflation rate $\left(\pi^{*}\right)$, ex-food and energy inflation rate, and median inflation rate published by the FRB of Cleveland. The series are 4-quarter (upper panel) and 12-quarter (lower panel) moving averages of (annualized) quarterly rates. Sample period starts in 1960(1) for the first two series and in 1967(4) for the median inflation measure, and ends in 2003(2) for all series. 